\title{
Expression and clinical significance of SATB1 and TLR4 in breast cancer
}

\author{
XUEBO WANG $^{1 *}$, XIUMEI YU ${ }^{1 *}$, QINGLI WANG ${ }^{2}$, YINGYING LU $^{3}$ and HAIXIA CHEN ${ }^{4}$ \\ ${ }^{1}$ Department of Clinical Laboratory, Yuhuangding Hospital of Yantai, Yantai, Shandong 264000; ${ }^{2}$ Department of Cardiology, \\ The People's Hospital of Zhangqiu, Zhangqiu, Shandong 250200; ${ }^{3}$ Department of Clinical Laboratory, \\ People's Hospital of Rizhao, Rizhao, Shandong 276800; ${ }^{4}$ Department of Clinical Laboratory, \\ Yeda Hospital of Yantai, Yantai, Shandong 264000, P.R. China
}

Received May 3, 2017; Accepted July 4, 2017

DOI: $10.3892 / \mathrm{ol} .2017 .6571$

\begin{abstract}
This study investigated the expression of special AT-rich sequence-binding protein 1 (SATB1) and toll-like receptor 4 (TLR4) protein in breast cancer and its clinical significance. We collected breast cancer tissues from 120 patients and adjacent non-cancerous tissue from 53 patients. SATB1 was expressed in 89 cases of breast cancer $(74.17 \%)$ and in 7 cases of adjacent non-cancerous tissue (13.21\%). TLR4 was expressed in 70 cases of breast cancer tissues $(58.33 \%)$ and in 48 cases of adjacent non-cancerous tissue (90.57\%). The differences of SATB and TLR4 in breast cancer and adjacent non-cancerous tissue were statistically significant. We found a negative correlation between the expression of SATB1 and TLR4 ( $\mathrm{r}=-0.624$, $\mathrm{P}<0.05)$. The expression of SATB1 and TLR4 were not significantly correlated with age, menopause, and PR and HER-2 protein expression, but were significantly correlated with tumor size, local lymphatic metastasis, histopathological grade, tumor stage, and ER protein expression $(\mathrm{P}<0.05)$. Overall, SATB1 and TLR4 proteins are involved in the development of breast cancer, a finding of great significance to identify therapeutic targets and prognosis markers for breast cancer.
\end{abstract}

\section{Introduction}

Breast cancer is one of the most common female malignant tumors with high morbidity and mortality rate caused by its strong metastatic ability $(1,2)$. There are no consensus biomarkers for early diagnosis and prognosis assessment of breast cancer with applications in clinical practice. Therefore, the development of breast cancer biomarkers has attracted

Correspondence to: Dr Haixia Chen, Department of Clinical Laboratory, Yeda Hospital of Yantai, 11 Taishan Road, Fushan, Yantai, Shandong 264000, P.R. China

E-mail: haixia_chen1@163.com

"Contributed equally

Key words: special AT-rich sequence-binding protein 1, toll-like receptor 4 , breast cancer increased attention recently. Special AT-rich sequence-binding protein 1 (SATB1) binds to T-rich sequences in chromosomes to regulate the expression of downstream genes $(3,4)$. The expression level of SATB1 is low in normal tissue, but is elevated in a variety of tumors (5-7). Toll-like receptor 4 (TLR4) is mainly expressed in immune cells, but can also be expressed in tumor cells (8-10). In this study, we detected the expression of SATB1 and RLR4 in 120 cases of cancer and 53 cases of adjacent non-cancerous tissue by immunohistochemistry. The correlation between the expression of these two proteins and the clinical characteristics of patients were analyzed.

\section{Patients and methods}

Patient information. A total of 120 patients diagnosed with breast cancer in Yuhuangding Hospital of Yantai from October 2014 to October 2016 was enrolled in the study. Cancer tissue was collected after surgical resection. At the same time, adjacent non-cancerous tissue was collected from 53 patients. All the patients were females, and their ages ranged from 28 to 65 years, with a mean age of $46.5 \pm 11.7$ years. No patient had been treated with chemotherapy before the study. Specimens were collected from necrotic cancer tissue and the adjacent non-cancerous tissue within $3 \mathrm{~cm}$, fixed, and embedded in paraffin. Cancerous samples were diagnosed as breast cancer by pathological examination. The study was approved by the Ethics Committee of Yuhuangding Hospital of Yantai. All the patients signed an informed consent before being enrolled in the study.

Reagents and methods. Anti-human SATB1 monoclonal antibody and rabbit anti-human TLR4 monoclonal antibody were purchased from Abcam (Cambridge, UK). The DAB kit and hematoxylin were purchased from ZSBG-Bio (Beijing, China). Horseradish peroxidase-conjugated secondary antibody was purchased from Santa Cruz Biotechnology, Inc. (Dallas, TX, USA). Paraffin-embedded breast cancer samples were cut into $4 \mu \mathrm{m}$ sections and transferred onto glass slides. After baking for $2 \mathrm{~h}$ at $90^{\circ} \mathrm{C}$, tissue sections were dewaxed and rehydrated. After that, antigen retrieval was performed by incubating with $0.01 \mathrm{M}$ sodium citrate buffer for $15 \mathrm{~min}$. Endogenous peroxidase blocker was then added and incubated at $37^{\circ} \mathrm{C}$ for 
Table I. Expression of SATB1 and TLR4 in breast cancer and adjacent non-cancerous tissue.

\begin{tabular}{|c|c|c|c|c|c|c|c|}
\hline \multirow[b]{2}{*}{ Groups } & \multirow[b]{2}{*}{ Cases (n) } & \multicolumn{3}{|c|}{ SATB1 } & \multicolumn{3}{|c|}{ TLR4 } \\
\hline & & - & + & Positive rate $(\%)$ & - & + & Positive rate (\%) \\
\hline Breast cancer & 120 & 31 & 89 & 74.17 & 50 & 70 & 58.33 \\
\hline Adjacent non-cancerous tissue & 53 & 46 & 7 & 13.21 & 5 & 48 & 90.57 \\
\hline$\chi^{2}$ value & & 37.413 & & 26.481 & & & \\
\hline P-value & & 0.006 & & 0.011 & & & \\
\hline
\end{tabular}

SATB1, special AT-rich sequence-binding protein 1; TLR4, toll-like receptor 4.
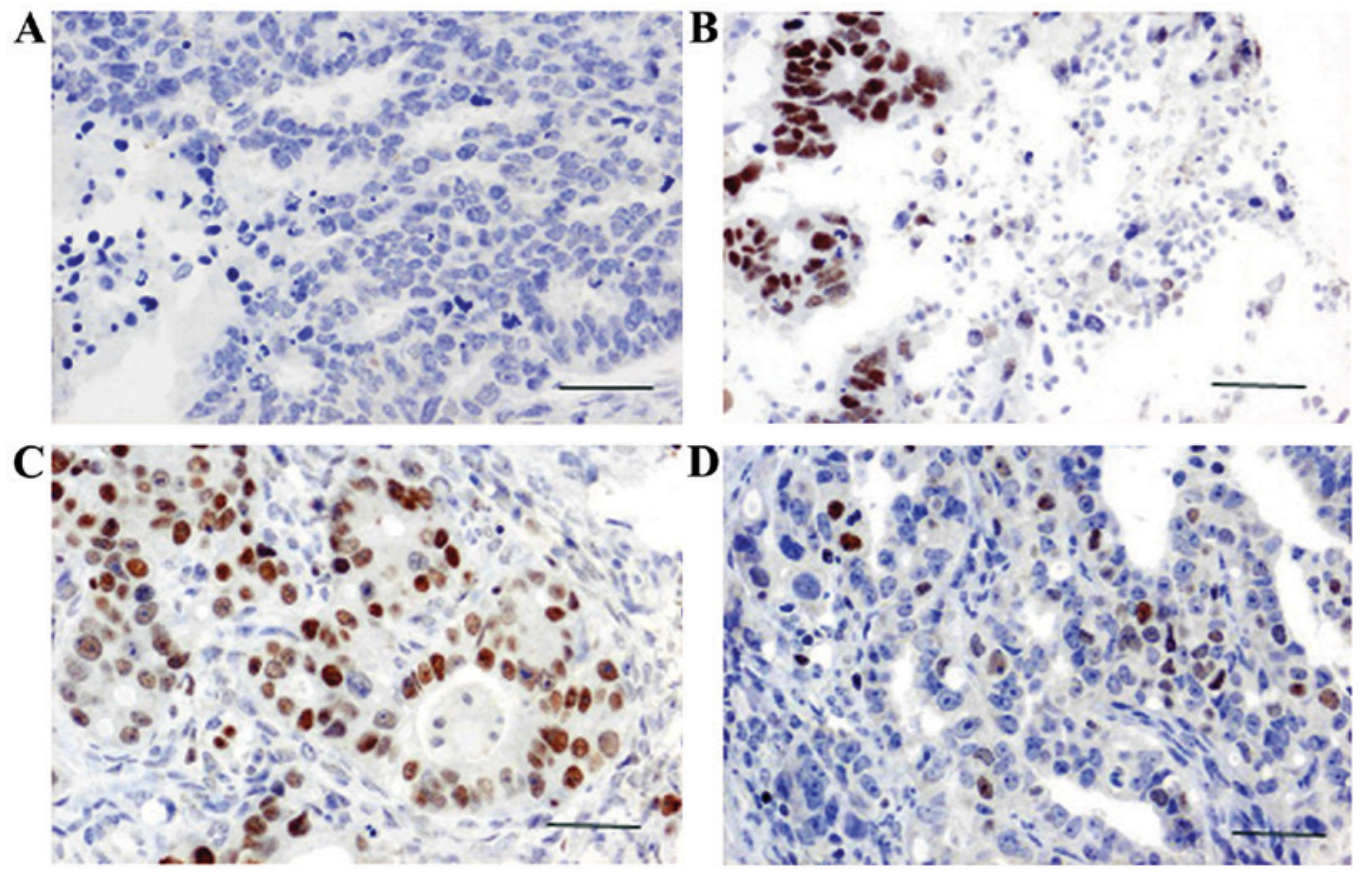

Figure 1. Expression of SATB1 and TLR4 in breast cancer and adjacent non-cancerous tissue. (A) Representative result of SATB1 expression in adjacent non-cancerous tissue (x400). (B) Representative result of SATB1 expression in breast cancer $(x 400)$. (C) Representative result of TLR4 expression in adjacent non-cancerous tissue (x400). (D) Representative result of TLR4 expression in breast cancer (x400). The positive expression rate of SATB1 in breast cancer tissues was significantly higher than that in adjacent non-cancerous tissue. The positive expression rate of TLR4 in adjacent non-cancerous tissues was significantly higher than that in breast cancer. SATB1, special AT-rich sequence-binding protein 1; TLR4, toll-like receptor 4.

$10 \mathrm{~min}$. After blocking with goat serum at room temperature for $20 \mathrm{~min}$, the primary antibodies of SATB1 (1:300) and TLR4 (1:300) were incubated with the slides at $4^{\circ} \mathrm{C}$ overnight. After washing, secondary antibody was added and incubated at $37^{\circ} \mathrm{C}$ for $1 \mathrm{~h}$. DAB staining was then performed and tissue sections were examined under the microscope to observe the staining. After hematoxylin staining, the slides were dehydrated, cleared, and sealed. All the operations were performed in accordance with the manufacturer's instructions.

Determination of experimental results. The brown or yellow granules on the slides showed the positive expression of SATB1 and TLR4. SATB1 mainly accumulated in the nucleus and TLR4 mainly accumulated in the cytoplasm. Using x400 magnification in a bright field microscope (Leica, Wetzlar, Germany), 10 distinct visual fields were selected to count the positive cells and record the degree of staining. We also calculated the percentage of positive cells. Scoring was performed
Table II. Correlation between the expression of SATB4 and TLR4 in breast cancer tissues.

\begin{tabular}{|c|c|c|c|c|}
\hline \multirow[b]{2}{*}{ TLR4 } & \multicolumn{2}{|c|}{ SATB1 } & \multirow[b]{2}{*}{ r value } & \multirow[b]{2}{*}{ P-value } \\
\hline & + & - & & \\
\hline+ & 43 & 27 & \multirow{2}{*}{-0.624} & \multirow{2}{*}{0.003} \\
\hline- & 46 & 4 & & \\
\hline
\end{tabular}

SATB1, special AT-rich sequence-binding protein 1; TLR4, toll-like receptor 4.

according to the degree of staining: no staining, 0 points; light yellow, 1 point; yellowish-brown, 2 points; chocolate brown, 3 points. Scoring was also performed according to the 
Table III. Correlation of the expression of SATB1 and TLR4 with the clinical and pathological features of patients.

\begin{tabular}{|c|c|c|c|c|c|c|c|}
\hline \multirow[b]{2}{*}{ Items } & \multirow[b]{2}{*}{ Cases (n) } & \multicolumn{3}{|c|}{ SATB1 } & \multicolumn{3}{|c|}{ TLR4 } \\
\hline & & + & $\chi^{2}$ value & P-value & + & $\chi^{2}$ value & P-value \\
\hline \multicolumn{8}{|c|}{ Age (years) } \\
\hline$<50$ & 46 & 35 & 0.25 & 0.416 & 28 & 0.74 & 0.352 \\
\hline$\geq 50$ & 74 & 54 & & & 42 & & \\
\hline \multicolumn{8}{|c|}{ Menopause } \\
\hline Yes & 52 & 38 & 1.36 & 0.129 & 30 & 0.62 & 0.391 \\
\hline No & 68 & 51 & & & 40 & & \\
\hline \multicolumn{8}{|c|}{ Tumor size } \\
\hline$<2 \mathrm{~cm}$ & 44 & 29 & 5.24 & 0.017 & 23 & 8.49 & 0.013 \\
\hline$\geq 2 \mathrm{~cm}$ & 76 & 60 & & & 47 & & \\
\hline \multicolumn{8}{|c|}{ Lymph node metastasis } \\
\hline Yes & 56 & 31 & 9.15 & 0.013 & 26 & 6.37 & 0.015 \\
\hline No & 64 & 57 & & & 44 & & \\
\hline \multicolumn{8}{|c|}{ Histopathological grade } \\
\hline I & 38 & 19 & 11.48 & 0.007 & 18 & 7.14 & 0.015 \\
\hline II & 53 & 44 & & & 36 & & \\
\hline III & 29 & 26 & & & 16 & & \\
\hline \multicolumn{8}{|c|}{ Tumor stage } \\
\hline I & 32 & 18 & 12.53 & 0.007 & 16 & 9.61 & 0.011 \\
\hline II & 57 & 43 & & & 33 & & \\
\hline III, IV & 31 & 28 & & & 21 & & \\
\hline \multicolumn{8}{|l|}{ PR } \\
\hline$(-)$ & 48 & 35 & 0.94 & 0.172 & 28 & 1.74 & 0.114 \\
\hline$(+)$ & 72 & 54 & & & 42 & & \\
\hline \multicolumn{8}{|l|}{ ER } \\
\hline$(-)$ & 53 & 29 & 6.74 & 0.015 & 24 & 7.93 & 0.013 \\
\hline$(+)$ & 67 & 60 & & & 46 & & \\
\hline \multicolumn{8}{|l|}{ HER-2 } \\
\hline$(-)$ & 52 & 38 & 0.87 & 0.181 & 30 & 0.96 & 0.172 \\
\hline$(+)$ & 68 & 51 & & & 40 & & \\
\hline
\end{tabular}

SATB1, special AT-rich sequence-binding protein 1; TLR4, toll-like receptor 4.

percentage of positive cells: $0-25 \%, 1$ point; $25-65 \%, 2$ points; $65-100 \%, 3$ points. The product of the 2 scores greater than 3 was taken as positive expression; values below 3 were considered negative expression (11).

Statistical analysis. SPSS 19.0 statistical software (IBM SPSS, Armonk, NY, USA) was used to analyze the data. The count data were analyzed by Chi-square test. Correlation analysis was performed by Spearman's rank correlation analysis. $\mathrm{P}<0.05$ was considered to be statistically significant.

\section{Results}

Expression of SATB1 and TLR4 in breast cancer and adjacent non-cancerous tissue. SATB1 expression was observed in the nucleus under a microscope. SATB1 was positively expressed in 89 cases of breast cancer, and the positive expression rate of SATB1 was $74.1 \%$ (Fig. 1). Positive expression of SATB1 was only detected in 7 cases of adjacent non-cancerous tissue, and the positive expression rate of SATB1 was $13.21 \%$. A statistically significant difference in the expression of SATB1 was found between breast cancer and adjacent non-cancerous tissue $(\mathrm{P}<0.05$; Table I).

TLR4 expression was detected in the cytoplasm. TLR4 was positively expressed in 70 cases of breast cancer, and the positive rate was $58.33 \%$ (Fig. 1). Positive expression of SATB1 was detected in 48 cases of adjacent non-cancerous tissues, and the positive rate was $90.57 \%$. A statistically significant difference in the expression of TLR4 was found between breast cancer and adjacent non-cancerous tissues $(\mathrm{P}<0.05$; Table I).

Correlation between expression of SATB1 and TLR4. Following the immunohistochemistry results, we next analyzed the correlation between SATB1 and TLR4. As shown 
in Table II, the expression of SATB1 was negatively correlated with the expression of TLR4 $(\mathrm{r}=-0.624, \mathrm{P}<0.05)$.

Correlation of SATB1 and TLR4 with the clinical and pathological features of patients. We last examined the correlation of the expression of SATB1 and TLR4, and the clinical and pathological features of patients. We found that the expression levels of SATB1 and TLR4 were not significantly correlated with the age, menopause, PR protein, and HER-2 protein expression $(\mathrm{P}>0.05)$. However, the expression levels of SATB1 and TLR4 were significantly correlated with tumor size, local lymphatic metastasis, histopathological grade, tumor stage, and the expression of ER protein $(\mathrm{P}<0.05$; Table III).

\section{Discussion}

SATB1 is a nuclear matrix attachment-binding protein with tissue-specific expression. The $S A T B 1$ gene is located on chromosome 3p23 and encodes for a 763-amino acid protein (12). SATB1 is highly expressed in thymus where it regulates the development and maturation of T cells $(13,14)$. Previous studies showed that $S A T B 1$ gene knockout in mice can inhibit the production of $\mathrm{CD}^{+}$and $\mathrm{CD}^{+}$double positive $\mathrm{T}$ cells, leading to disorders of thymus cell maturation (15). SATB1 plays a role as a 'gene organizer' in the genome. SATB1 can interact with more than 1,000 proteins to specifically regulate the expression of its target genes by chromatin remodeling and protein modification (16). SATB1 can bind the BUR region of target genes and anchor the BUR region on the nuclear matrix to alter the higher-order structure of the chromatin, and regulate gene expression (17). SATB1 can also regulate DNA binding capacity and the subcellular localization of proteins through phosphorylation, ubiquitination, and acetylation (18). Liu et al found that high expression of SATB1 in breast cancer cells significantly increased cell invasion ability (19). Clinical data from 1,318 breast cancer patients showed that the expression level of SATB1 was negatively correlated with survival time (20). Our study shows that SATB1 is strongly expressed in breast cancer and weakly expressed in adjacent non-cancerous tissue. The expression of SATB1 was not significantly correlated with age, menopause, and the expression of the PR and HER-2 proteins, but was significantly correlated with tumor size, local lymphatic metastasis, histopathological grade, tumor stage, and ER protein expression. Our findings are consistent with previous studies $(21,22)$.

Toll-like receptors were first found in Drosophila. In 1997, TLR4 homologue was identified in humans, and so far, there are 12 members of the TLRs family (23). The TLR4 gene is located on chromosome 9q32-q33, and encodes for a 224-amino acid protein. TLR4 is widely distributed on the cell surface to sense pathogens (24). TLR4 is widely distributed in human monocytes (25), neutrophils (26), and epithelial cells (27). TLR4 can recognize a variety of pathogen-associated molecular patterns (e.g., LPS of Gram-negative bacteria) to induce different immune responses (28). Through binding to the corresponding ligands and mediating intracellular signal transduction, TLR4 plays a role as a transcription factor to activate the expression of a variety of cell growth and apoptosis-related factors (29,30). TLR4 can mediate MyD88-dependent pathways through the interaction with a series of cytokines to promote tumorigenesis (31). Clinical studies also found that TLR4 was correlated with the growth and metastasis of gastric cancer (32), ovarian cancer $(33,34)$, cervical cancer (35), and other types of tumor cells. In our study, we found that TLR4 was positively expressed in $58.33 \%$ cases of breast cancer tissues and in $90.57 \%$ cases of adjacent non-cancerous tissue. The positive expression rate of TLR4 in this study is consistent with previous studies $(35,36)$. We also found that TLR4 expression was not significantly correlated with age, menopause, or the expression of the PR and HER-2 proteins. However, TLR4 was significantly correlated with tumor size, local lymphatic metastasis, histopathological grade, tumor stage, and ER protein expression. In addition, correlation analysis indicated that the expression level of SATB1 was negatively correlated with the expression level of TLR4. In conclusion, SATB1 and TLR4 are involved in the development of breast cancer, which is of great significance for the identification of potential therapeutic targets and prognosis of breast cancer.

\section{References}

1. Elkin EB, Pocus VH, Mushlin AI, Cigler T, Atoria CL and Polaneczky MM: Facilitating informed decisions about breast cancer screening: Development and evaluation of a web-based decision aid for women in their 40s. BMC Med Inform Decis Mak 17: 29, 2017.

2. Crop F, Pasquier D, Baczkiewic A, Doré J, Bequet L, Steux E, Gadroy A, Bouillon J, Florence C, Muszynski L, et al: Surface imaging, laser positioning or volumetric imaging for breast cancer with nodal involvement treated by helical TomoTherapy. J Appl Clin Med Phys 17: 1-12, 2016.

3. Wu D, Zeng L, Liu F, Zhong Q, Zhang D, Cai C, Zhang W, Wu L and Chen H: Special AT-rich DNA-binding protein-1 expression is associated with liver cancer metastasis. Oncol Lett 12: 4377-4384, 2016.

4. Stephen TL, Payne KK, Chaurio RA, Allegrezza MJ, Zhu H, Perez-Sanz J, Perales-Puchalt A, Nguyen JM, Vara-Ailor AE, Eruslanov EB, et al: SATB1 expression governs epigenetic repression of PD-1 in tumor-reactive T cells. Immunity 46: 51-64, 2017.

5. Li YC, Bu LL, Mao L, Ma SR, Liu JF, Yu GT, Deng WW, Zhang WF and Sun ZJ: SATB1 promotes tumor metastasis and invasiveness in oral squamous cell carcinoma. Oral Dis 23: 247-254, 2017.

6. Lee JJ, Kim M and Kim HP: Epigenetic regulation of long noncoding RNA UCA1 by SATB1 in breast cancer. BMB Rep 49: 578-583, 2016.

7. Gottimukkala KP, Jangid R, Patta I, Sultana DA, Sharma A, Misra-Sen J and Galande S: Regulation of SATB1 during thymocyte development by TCR signaling. Mol Immunol 77 : 34-43, 2016.

8. Lim SG, Kim JK, Suk K and Lee WH: Crosstalk between signals initiated from TLR4 and cell surface BAFF results in synergistic induction of proinflammatory mediators in THP-1 cells. Sci Rep 7: 45826, 2017.

9. Wu KC, Huang SS, Kuo YH, Ho YL, Yang CS, Chang YS and Huang GJ: Ugonin M, a Helminthostachys zeylanica constituent, prevents LPS-induced acute lung injury through TLR4-mediated MAPK and NF-кB signaling pathways. Molecules 22: E573, 2017.

10. Simundic T, Jelakovic B, Dzumhur A, Turk T, Sahinovic I, Dobrosevic B, Takac B and Barbic J: Interleukin 17A and Toll-like receptor 4 in patients with arterial hypertension. Kidney Blood Press Res 42: 99-108, 2017.

11. Kowalczyk AE, Krazinski BE, Godlewski J, Grzegrzolka J, Kiewisz J, Kwiatkowski P, Sliwinska-Jewsiewicka A, Dziegiel P and Kmiec Z: SATB1 is down-regulated in clear cell renal cell carcinoma and correlates with miR-21-5p overexpression and poor prognosis. Cancer Genomics Proteomics 13: 209-217, 2016.

12. Dickinson LA, Joh T, Kohwi Y and Kohwi-Shigematsu T: A tissue-specific MAR/SAR DNA-binding protein with unusual binding site recognition. Cell 70: 631-645, 1992.

13. Nixon BG and Li MO: Satb1: Restraining PD1 and T cell exhaustion. Immunity 46: 3-5, 2017. 
14. Kitagawa Y, Ohkura N, Kidani Y, Vandenbon A, Hirota K, Kawakami R, Yasuda K, Motooka D, Nakamura S, Kondo M, et al: Guidance of regulatory T cell development by Satb1-dependent super-enhancer establishment. Nat Immunol 18: 173-183, 2017.

15. Kondo M, Tanaka Y, Kuwabara T, Naito T, Kohwi-Shigematsu T and Watanabe A: SATB1 plays a critical role in establishment of immune tolerance. J Immunol 196: 563-572, 2016.

16. Song G, Liu K, Yang X, Mu B, Yang J, He L, Hu X, Li Q, Zhao Y, Cai X and Feng G: SATB1 plays an oncogenic role in esophageal cancer by up-regulation of FN1 and PDGFRB. Oncotarget 8 17771-17784, 2017.

17. Luan QX, Zhang BG, Li XJ and Guo MY: MiR-129-5p is downregulated in breast cancer cells partly due to promoter $\mathrm{H} 3 \mathrm{~K} 27 \mathrm{~m} 3$ modification and regulates epithelial-mesenchymal transition and multi-drug resistance. Eur Rev Med Pharmacol Sci 20 4257-4265, 2016.

18. Yuan CL, Li L, Zhou X, Liz H and Han L: Expression of SATB1 and HER 2 in gastric cancer and its clinical significance. Eur Rev Med Pharmacol Sci 20: 2256-2264, 2016.

19. Liu X, Zheng Y, Qiao C, Qv F, Wang J, Ding B, Sun Y and Wang Y: Expression of SATB1 and HER2 in breast cancer and the correlations with clinicopathologic characteristics. Diagn Pathol 10: 50, 2015.

20. Han HJ, Russo J, Kohwi Y and Kohwi-Shigematsu T: SATB1 reprogrammes gene expression to promote breast tumour growth and metastasis. Nature 452: 187-193, 2008.

21. Roberts MR, Sucheston-Campbell LE, Zirpoli GR, Higgins M, Freudenheim JL, Bandera EV, Ambrosone CB and Yao S: Single nucleotide variants in metastasis-related genes are associated with breast cancer risk, by lymph node involvement and estrogen receptor status, in women with European and African ancestry. Mol Carcinog 56: 1000-1009, 2017.

22. Pan Z, Jing W, He K, Zhang L and Long X: SATB1 is correlated with progression and metastasis of breast cancers: A meta-analysis. Cell Physiol Biochem 38: 1975-1983, 2016.

23. Medzhitov R, Preston-Hurlburt P and Janeway CA Jr: A human homologue of the Drosophila toll protein signals activation of adaptive immunity. Nature 388: 394-397, 1997.

24. Akira S, Uematsu S and Takeuchi O: Pathogen recognition and innate immunity. Cell 124: 783-801, 2006.

25. Galdino H Jr, Saar Gomes R, Dos Santos JC, Pessoni LL, Maldaner AE, Marques SM, Gomes CM, Dorta ML, de Oliveira MA, Joosten LA, et al: Leishmania (Viannia) braziliensis amastigotes induces the expression of TNF $\alpha$ and IL-10 by human peripheral blood mononuclear cells in vitro in a TLR4-dependent manner. Cytokine 88: 184-192, 2016.
26. Yan B, Chen F, Xu L, Xing J and Wang X: HMGB1-TLR4-IL23IL17A axis promotes paraquat-induced acute lung injury by mediating neutrophil infiltration in mice. Sci Rep 7: 597, 2017.

27. Imai H, Fujita T, Kajiya M, Ouhara K, Yoshimoto T, Matsuda S, Takeda K and Kurihara H: Mobilization of TLR4 into lipid rafts by Aggregatibacter Actinomycetemcomitans in gingival epithelial cells. Cell Physiol Biochem 39: 1777-1786, 2016.

28. Schüller SS, Wisgrill L, Herndl E, Spittler A, Förster-Waldl E, Sadeghi K, Kramer BW and Berger A: Pentoxifylline modulates LPS-induced hyperinflammation in monocytes of preterm infants in vitro. Pediatr Res: May 24, 2017 (Epub ahead of print).

29. Liu S, Wang X, Shi Y, Han L, Zhao Z, Zhao C and Luo B: Toll-like receptor gene polymorphisms and susceptibility to Epstein-Barr virus-associated and -negative gastric carcinoma in Northern China. Saudi J Gastroenterol 21: 95-103, 2015.

30. Haricharan S and Brown P: TLR4 has a TP53-dependent dual role in regulating breast cancer cell growth. Proc Natl Acad Sci USA 112: E3216-E3225, 2015.

31. Wang D, Taylor GM, Gilbert JR, Losee JE, Sodhi CP, Hackam DJ, Billiar TR and Cooper GM: Enhanced calvarial bone healing in CD11c-TLR4 ${ }^{-/}$and MyD88 ${ }^{-/}$mice. Plast Reconstr Surg 139: 933e-940e, 2017.

32. Tian Y, Li X, Li H, Lu Q, Sun G and Chen H: Astragalus Mongholicus regulate the toll-like-receptor 4 meditated signal transduction of dendritic cells to restrain stomach cancer cells Afr J Tradit Complement Altern Med 11: 92-96, 2014.

33. Klink M, Nowak M, Kielbik M, Bednarska K, Blus E, Szpakowski M, Szyllo K and Sulowska Z: The interaction of HspA1A with TLR2 and TLR4 in the response of neutrophils induced by ovarian cancer cells in vitro. Cell Stress Chaperones 17: 661-674, 2012.

34. Wang AC, Ma YB, Wu FX, Ma ZF, Liu NF, Gao R, Gao YS and Sheng XG: TLR4 induces tumor growth and inhibits paclitaxel activity in MyD88-positive human ovarian carcinoma in vitro. Oncol Lett 7: 871-877, 2014.

35. de Matos LG, Cândido EB, Vidigal PV, Bordoni PH, Lamaita RM, Carneiro MM and da Silva-Filho AL: Association between toll-like receptor and tumor necrosis factor immunological pathways in uterine cervical neoplasms. Tumori 103: 81-86, 2017.

36. He A, Ji R, Shao J, He C, Jin M and Xu Y: TLR4-MyD88TRAF6-TAK1 complex-mediated NF- $\kappa \mathrm{B}$ activation contribute to the anti-inflammatory effect of V8 in LPS-induced human cervical cancer SiHa cells. Inflammation 39: 172-181, 2016. 